\title{
Toward Augmented Reality Displays for Sports Spectators: A Preliminary Study ${ }^{\dagger}$
}

\author{
Clara Hertzog *, Sho Sakurai, Koichi Hirota and Takuya Nojima \\ Department of Informatics, University of Electro-Communications, Chofu, Tokyo 182-8585, Japan; \\ sho@vogue.is.uec.ac.jp (S.S.); hirota@vogue.is.uec.ac.jp (K.H.); tnojima@nojilab.org (T.N.) \\ * Correspondence: clara.hertzog@vogue.is.uec.ac.jp; Tel.: +81-42-443-5000 \\ + Presented at the 13th Conference of the International Sports Engineering Association, Online, 22-26 June 2020. \\ Published: 15 June 2020
}

\begin{abstract}
The sports industry and researchers work on improving spectators' enjoyment to influence their consumption behavior. Many studies evaluated the variables impacting on enjoyment, but they did not consider the recent new technologies popularization. This study aims to update these considerations and reevaluate enjoyment parameters' impact, considering display technologies use. Most of the previous research works identified identification to the players and teams as the most powerful enjoyment variable, but considering our survey results, participants cared more about the game understanding parameter, and manifested the wish to improve it via a display.
\end{abstract}

Keywords: sports spectator experience; enjoyment parameters; augmented reality display

\section{Introduction}

In the sports area, researchers and companies focus on optimizing spectators' enjoyment to influence their consumption behavior. Indeed, for every sports competition, there are spectators and a potential profitable business. When spectators' attendance increases, teams can improve their secondary income, with broadcasting rights, use of team logos, media productions, etc. [1]. A possible way to do so is to influence the spectators' enjoyment.

Enjoyment can be defined as the "pleasure response to entertainment media" according to Tamborini's research works [2]. To assess sports spectators' enjoyment, researchers have adopted different methods: enjoyment scoring, spectators' reactions study, game attendance study, etc. $[1,3,4]$.

When witnessing a sports game, enjoyment is generated according to a variety of personal and external factors. Identification to the teams or players is one of them for example, largely developed in Zillmann's research works [5]. They also pointed out how the intention, such as struggle or competitive mind, of the players could impact on spectators' enjoyment. Zhang's research works [1] grouped all the enjoyment factors identified by previous researches into three groups: "Party Ambiance (4 items - 'amusement activities', 'players appeal', 'music', and 'speed of game'), Game Feature (3 items - 'tough/aggressive play', 'player fighting', and 'promotions/give-aways'), and Socializing Opportunity (2 items-'socializing with friends' and 'people watching')".

However, it appears that they did not consider the spectator's game understanding factor in this research. Moreover, these studies have been conducted many years ago and did not follow the popularization of new technologies. Spectators can visualize on augmented displays information about rules, penalties, scored points, etc. [6-10]. Spectators can have access to information about the performing players via television or their smartphone [11,12]. Online platforms are now accessible to spectators to share their reactions remotely [13]. Visual effects are displayed to dynamism the action [14], and so on. These last few years, societies and researchers have developed systems to improve 
enjoyment through the improvement of spectators' game understanding, identification to teams or players, reaction sharing, and game dynamism.

In this study, we consider these four enjoyment parameters, and we aim to reevaluate them and their impact on enjoyment, considering augmented reality displays services.

To evaluate enjoyment variables considering new technologies impact, we redefine the main enjoyment variables: game understanding, increased thanks to game information display, teams or players identification, optimized thanks to teams or players information display, reaction sharing, eased by online platforms and spectators' reaction displays, and game dynamism, augmented by sounds effects, visual effects, etc. These variables are the enjoyment variables considered in this study, that have been improved by researchers or companies using television display, smartphone, Virtual Reality (VR), or Augmented Reality (AR). More explanations about these parameters are given in the next section of this paper.

Common factors influencing sports spectators' enjoyment can be identified for every kind of sport, but depending on the type of sport, spectators will have different expectations, and enjoyment factors will not have the same impact. Therefore, categorizing sports is necessary to study sports spectators' enjoyment [3].

In our study, we choose to focus on the "aggressive team sports" cluster defined in Sargent paper [3]. This cluster contains soccer, basketball, and baseball. These sports are team sports, characterized by direct physical contacts, confrontations, and a level of contact considered as aggressive. Regarding this definition, we also add rugby and handball to this group. We chose to focus on this category, which gathers several of the most popular sports in Japan such as soccer or baseball [15].

\section{Augmented Reality Displays and Parameters Impacting Enjoyment}

In this section, we aim to enlighten the four considered enjoyment variables: game understanding, identification to the players or teams, reaction sharing, and game dynamism.

\subsection{Game Understanding}

Understanding a sports game means understanding the actions of the players, the progress of the match, etc. Traditionally, it requires minimal knowledge about the rules, and experience to be able to understand the progress of the ongoing game. However, beginners usually have little knowledge of the rules or strategies. Thus, they tend to feel confused or frustrated and lose enjoyment while watching the match. Many researchers and companies understood this issue, and many display systems and solutions are now available to spectators to improve game understanding and enjoyment. We give some examples of display systems in the following paragraph.

To ease game understanding, the research works of Kawamura, Han, and Koyama aim to improve sports broadcasting [6-9]. The developed systems display the game from different points of view. Free-viewpoint broadcasting can offer the possibility to visualize the game from a better point of view and clarify the action. The point here is to improve spectators' understanding of the ongoing game.

Other displays propose to visualize augmenting information merged to the game, such as Cavallaro's system [10]. It focuses on television broadcasting and proposes easy and clear displays using tracking. The point is again to show information to ease spectators' understanding.

These systems are given new resources to spectators and support them to better understand the game. Displays improvement gives to spectators a different experience from traditional spectators, and generates a different enjoyment, related to the features and efficiency of the used display system.

\subsection{Identification to Players and/or Teams}

The more spectators like a sports team, the more they commit to the game and feel enjoyment and excitement watching them perform. Indeed, according to Zhang's [1] and Zillmann's [5] research works, spectators particularly enjoy a sports game when an appreciated team defeats a disliked one, and vice versa. In this case, it would be possible to influence spectators' enjoyment by encouraging 
their identification to players and teams. To do so, a solution is to increase spectators' knowledge about the teams and players. This is why many companies are already proposing many means to inform spectators about teams' and players' data.

In Bielli and Mahmood's research works [12,13], they propose systems that can superimpose players' information on the player's image on a smartphone or tablet.

The purpose of these research works is to give personalized and specific information about the players on the field to spectators. A spectator provided with information about the teams and players is more likely to feel concerned by the game, to commit in the match, and to increase his enjoyment.

\subsection{Reaction Sharing}

When watching a sports game with other people and sharing reactions, spectators' enjoyment is impacted. In Zhang's research work [1], they describe from previous research works that spectators "have a sense of commitment, support, and alliance, as well as they shared interests, knowledge, and excitement", and they could verify the hypothesis that "sociodemographics would affect game enjoyment". However, another influence they did not consider game enjoyment is social networks impact. People traditionally gather to watch a sports game to get better enjoyment, but nowadays they also use various platforms to interact remotely with other spectators. Thanks to television, smartphones, VR, or AR, the reaction sharing variable is getting a new dimension, and to study its influence on enjoyment, it is important to also consider the impact of technologies.

As an example, Lee's research works [13] present a VR platform for spectators to share their reactions. With this platform, spectators are emerged in a virtual and remoted collective atmosphere, and appeared to be largely satisfied with this system.

So, spectators using social virtual platforms have a different spectator experience, and enjoyment.

\subsection{Game Dynamism}

A dynamic game is defined as a game that gives a feeling of vigorous activity and progress. Game dynamism is generated by several possible factors. It is mainly related to game features: competitive mind, struggle, show of skills, etc. This feeling can also be increased by external elements contributing to a dynamic atmosphere: noise, suspense, hum, etc. These factors we have mentioned have been cited as enjoyment factors in Zhang's research works [1], and they contribute to game dynamism. Thus, we consider game dynamism as an important enjoyment parameter.

Display design and visual effects can be used to give to the action more dynamism, and dynamics, according to Vorderer's research work [16], is a prerequisite of enjoyment in media consumption. So, designing displays to optimize game dynamism can consequently improve spectators' enjoyment.

Nowadays, companies and researchers in the sports area do not focus on this solution to improve spectators' enjoyment. However, in the Augmented Sports field, visual effects are often used to increase players' and spectators' enjoyment. One example of Augmented Sports affecting the dynamism is HADO. HADO sport is an Augmented Sport using visual effects [14]. During a game, players of HADO throw an "energy ball" against their enemies to defeat them. Those virtual objects and necessary supplemental information are displayed through AR devices. In this sport, the display is crucial, so the design is highly developed. It shows plenty of lights, colors that give the game a lot of dynamism.

Using visual effects increases game dynamism, augments spectators' experience, and provides new means to improve enjoyment.

\section{Related Works}

The emergence of new technologies pushed researchers to get concerned about the combination of sport and new technologies [6-14], and have changed spectators' media consumption. However, only a few focused on the question of how the use of technologies while watching a game impacts on spectators' enjoyment. Many researchers these past decades studied the variables impacting on 
spectators' enjoyment [1,3-5], but none of these studies have been updated and considered display technologies use in their enjoyment studies.

Rogers's research works $[17,18]$ consider this new parameter, and deal with sport spectators, augmented reality displays, and enjoyment. They explain how augmented reality displays can be used to improve enjoyment. However, in these studies, they focus on devices and only partially on the enjoyment parameters. They focus on the question of how to display augmented information, especially in the case of information seeking, but the other enjoyment parameters are not discussed. They conclude that enjoyment is actually not especially related to the kind of used device, but can highly contribute to harm it. Indeed, the spectator can face confusion and frustration while trying to use an unknown device and in the same way lose enjoyment. However, this consideration only concerns information seeking, so the augmentation of the game understanding variable.

Our study aims to identify and evaluate the enjoyment parameters, considering augmented reality displays impact.

\section{Evaluation}

\subsection{Method}

To know how each parameter impacts attendance while watching a sports game, and to what extent new technologies can improve them, a survey has been conducted. The questionnaire has been published online and 31 people were asked to answer it after watching a game of soccer, basketball, baseball, handball, or rugby. These people were between 18 and 60 years old, 26.1 years old on average, and $83.9 \%$ were men. About nationalities, $65.1 \%$ were Japanese, $32.2 \%$ were French, and $2.7 \%$ were from other countries. They all gathered through SNS service. This survey had two goals:

- Preliminary investigates the sample's technological background, and the next section evaluates the impact on their enjoyment of game understanding, identification to the teams or players, and reaction sharing during the game. The purpose is to reveal the current needs and state of the spectators, considering their access to their smartphone or internet. This section also investigates the impact of these parameters on their enjoyment.

- Game dynamism appeared to be mainly related to game features and interviewed spectators did not use any display system to increase their perception of dynamism. Considering the aim of this part, it would not have been relevant to evaluate a parameter that would not have been impacted by technologies. So, the questions have only been asked to reevaluate game understanding, identification to the teams or players, and reaction sharing parameters. The game dynamism parameter has been considered later in the survey.

- In spite of spectators' access to their smartphone or internet, we also aimed to evaluate the remaining spectators' needs. The purpose of this section is to identify the possible improvements of each parameter through displays (television, smartphone, VR, AR).

\subsection{Results}

The questionnaire was composed of three parts. For every 1-10 scale question, 1 represents the minimum score and 10 the maximum one.

- The first part aimed to learn more about the participants' background, and their habits and familiarity with display technologies:

- The average answer to the question Q1 “On a scale from 1 to 10, would you tell you are familiar with new technologies? (smartphone, Virtual Reality, ...)" was 7.7, with a variance of 2.1.

- The average answer to the question Q2 "On a scale from 1 to 10, how comfortable are you with new technologies such as smartphone or others?" was 8.4, with a variance of 1.7 .

- We also asked them about the frequency they used their phone during the game. The results are shown in Figure 1. 


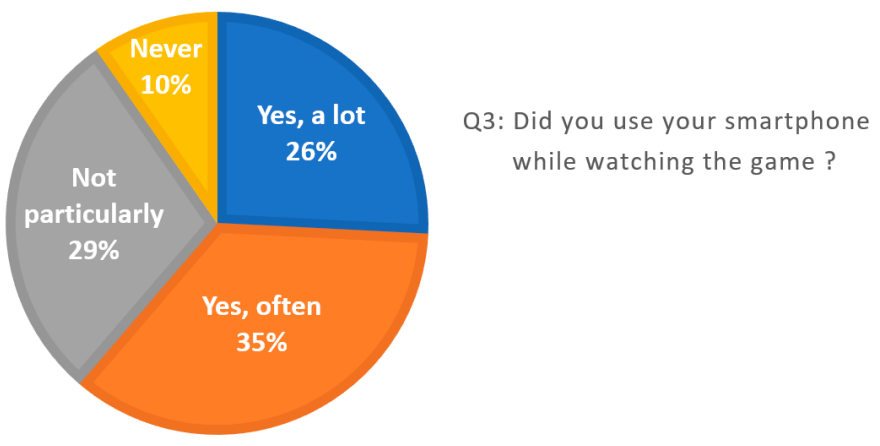

Figure 1. Results to the question about using smartphone while watching the game.

- After inquiring about the technological background of the interviewee, we asked them if they thought their game understanding, knowledge about the players and teams, or reaction sharing with other spectators "[...] has impacted on [their] enjoyment during the game".

- About game understanding: 61.3\% thought it has impacted, 29\% thought maybe, $6.5 \%$ thought no, and $3.2 \%$ had no opinion.

- $\quad$ About knowledge about teams or players: $41.9 \%$ thought yes, $19.4 \%$ maybe, $29 \%$ no, and $9.7 \%$ had no opinion.

- About reaction sharing: $45.2 \%$ answered yes, $22.6 \%$ maybe, $16.1 \%$ no, and $16.1 \%$ no opinion.

- After evaluating the enjoyment parameters' impact, we asked the participants if they would improve one of the enjoyment parameters using display (television, smartphone, VR, or AR). The results are shown in Figure 2.

Q4: Would use a special display to ...



Figure 2. Percentages of the interviewees who would use a special display to improve one of the enjoyment parameters (television, smartphone, virtual reality (VR), or augmented reality (AR)).

\subsection{Discussion}

Regarding our data, we consider that the participants constitute a sample familiar to display technologies such as smartphones. Considering this background, we reevaluated the impact of parameters based on self-scoring. The majority of the interviewees thought that game understanding has impacted enjoyment, and only a few replied that they did not think so. In previous studies, identification to players or teams appeared to be the most impacting parameter on enjoyment, but in our study, the most impacting variable turned to be game understanding.

This parameter is also the one the participants would like to improve the most using display such as smartphone, television, VR, or AR.

\section{Conclusions}

Most of the previous research work studying enjoyment parameters considered identification to the players and teams as the parameter generating higher enjoyment for sports spectators $[1,5]$. However, considering our results, game understanding is the parameter that should be considered in priority about enjoyment improvement. Roger's research works $[17,18]$ evaluated the impact on the enjoyment of the display technologies used while watching a game. They only considered the information-seeking aspect, but in the case they displayed information about game progress, this 
choice was particularly pertinent. According to our results, they turned to reply to a need and influence the most impacting enjoyment parameter considering technology use.

We also showed the wish and needs of the participants to improve enjoyment using a special display. Many research works intended to meet this need by displaying different kinds of content. However, only a few focused on improving game dynamism, using visual effects. For the next actions, we plan to evaluate how visual effects display can influence game dynamism and spectators' enjoyment.

Author Contributions: C.H. contributed to the design and implementation of the research, to the analysis of the results and to the writing of the manuscript. T.N. helped supervise the project and contributed to the final version of the manuscript. All authors provided critical feedback and helped shape the research.

Funding: This research received no external funding.

Conflicts of Interest: The authors declare no conflict of interest.

\section{References}

1. Zhang, J.J.; Lam, E.T.C.; Connaughton, D.P.; Bennet, G.; Pease, D.G.; Pham, U.L.; Killion, L.E.; Ocker, L.B.; Duley, A.R. Variables affecting spectator enjoyment of minor league hockey games. Int. J. Sport Manag. 2004, 5, 157-182.

2. Tamborini, R.; Bowman, N.D.; Eden, A.; Grizzard, M.; Organ, A. Defining media enjoyment as the satisfaction of intrinsic needs. J. Commun. 2010, 60, 758-777.

3. Sargent, S.; Zillmann, D.; Weaver, J. The gender gap in the enjoyment of televised sports. J. Sport Soc. Issues 1998, 22, 46-64.

4. Gunter, B. Sports, violence, and the media. In Handbook of Sports and Media; Raney, A.A., Bryant, J., Eds.; Routledge: Abingdon-on-Thames, UK, 2009.

5. Zillmann, D.; Bryant, J; Sapolsky, B.S. Enjoyment from sports spectatorship. In Sports, Games, and Play: Social and Psychological Viewpoints, 2nd ed.; Goldstein, J.H., Ed.; Psychology Press: New York, NY, USA, 1989.

6. Kawamura, Y.; Otsuki, K. 3D free-viewpoint augmented reality on a second display synchronized with a broadcast program. In Proceedings of the 4th International Conference on Communication and Information Processing, Qingdao, China, 2-4 November 2018; pp. 273-277, doi:10.1145/3290420.3290449.

7. Han, J.; Farin, D.; De With, P.H.N. A real-time augmented-reality system for sports broadcast video enhancement. In Proceedings of the 15th ACM International Conference on Multimedia, Augsburg, Germany, 24-29 September 2007; pp. 337-340, doi:10.1145/1291233.1291306.

8. Han, J.; Farin, D.; De With, P. A mixed-reality system for broadcasting sports video to mobile devices. IEEE Multimed. 2011, 18, 72-84.

9. Koyama, T.; Kitahara, I.; Ohta, Y. Live mixed-reality 3D video in soccer stadium. In Proceedings of the 2nd IEEE and ACM International Symposium on Mixed and Augmented Reality, ISMAR 2003, Tokyo, Japan, 10 October 2003; pp. 178-186.

10. Cavallaro, R.; Hybinette, M.; White, M.; Balch, T. Augmenting live broadcast sports with 3D tracking information. IEEE Multimed. 2011, 18, 38-47.

11. Bielli, S.; Harris, C.G. A mobile augmented reality system to enhance live sporting events. In Proceedings of the 6th Augmented Human International Conference, Singapore, 9-11 March 2015; pp. 141-144.

12. Mahmood, Z.; Ali, T.; Khattak, S.; Hasan, L.; Khan, S.U. Automatic player detection and identification for sports entertainment applications. Pattern Anal. Appl. 2015, 18, 971-982.

13. Lee, H.; Ha, G.; Lee, S.; Kim, S. A mixed reality tele-presence platform to exchange emotion and sensory information based on MPEG-V standard. In Proceedings of the IEEE Virtual Reality, Los Angeles, CA, USA, 18-22 March 2017; pp. 349-350.

14. HADO Augmented Dodgeball Official Website. Available online: hado-asia.com (accessed on 31 October 2019).

15. CRS, Dai 27 kai. Ninki supotsu chosa [27th Most Popular Sports Surveillance], 2019. Available online: https://www.crs.or.jp/data/pdf/sports19.pdf (accessed on 19 May 2020)

16. Vorderer, P.; Klimmt, C.; Ritterfeld, U. Enjoyment: At the heart of media entertainment. Commun. Theory 2004, 14, 388-408. 
17. Rogers, R.; Strudler, K.; Decker, A.; Grazulis, A. Does augmented reality augment the experience? A qualitative analysis of enjoyment for sports spectators. Media Watch 2019, 10, 664-674.

18. Rogers, R.; Strudler, K.; Decker, A.; Grazulis, A. Can augmented-reality technology augment the fan experience? A model of enjoyment for sports spectators. J. Sports Media 2017, 12, 22-44.

(C) 2020 by the authors. Licensee MDPI, Basel, Switzerland. This article is an open access article distributed under the terms and conditions of the Creative Commons Attribution (CC BY) license (http://creativecommons.org/licenses/by/4.0/). 